\title{
Evidence for all-or-none preperceptual processing in perceptual set*
}

\author{
CARL ALIERBACH and GLORIA LEVENTHAL $\div$ \\ Yeshiva Liniversity. 55 Fifth Alenue. lew York. lew York 10003
}

\begin{abstract}
"Set" is known to improve the accuracy of report of the stimulus attributes for which Ss are set to respond. The set may produce this effect by acting on either preperceptual or postperceptual processes. or both. To elucidate the manner by which set produces its effect. this paper explores the consequences of two assumptions concerning set: (1) On any given trial. a $S$ is either "set" or "not set": (2) if "set" by the stimulus intormation. S's perception of the stimulus actually improres, whereas. if "not set" by the stimulus information. the S's report correctness is improved by an independent interaction of stimulus and set information on a response process. Evidence is provided for both these assumptions. In addition. it is argued that only set given before stimulation can affect a perceptual process.
\end{abstract}

In this paper. we use the term "set" to refer to information given to a subject which restricts either the range of possible stimuli from which the stimulus he is presented has been drawn or the range of possible attributes of the stimulus to which he must respond. Thus, a subiect in an auditory experiment presented with four tones and told that one of them will be the stimulus he will hear is "set" to perceive one of the four tones (cf. Swets \& Sewall. 1963), and a subject in a visual experiment told that he will be asked to report the color of a visual pattern is "set" to perceive color (cf. Kulpe, 1904).

Set to report a stimulus or an attribute of a stimulus increases the probability of a correct report over the probability when no set is administered. Kulpe (1904) first established this fact. and subsequent investigators have replicated his basic finding. [See Egeth (1967) and Haber (1966) for reviews of this literature, and for further elaboration of many of the following points.] There are at least two alternative hypotheses as to the nature of the effect of set on perception. The preperceptual hy pothesis is that set acts to increase the clarity of the perception of the stimulus or stimulus attribute the $\mathrm{S}$ is set to report. The postperceptual hypothesis is that set acts after perception to improve performance by any of several mechanisms, including altering encoding or report strategies or reducing the number of response alternatives.

The present paper has three aims. First, to state the prestimulation and poststimulation hypotheses in terms of a simple mathematical model for perceptual set, essentially analogous to two-state detection theories

\footnotetext{
*Portions of this research were supported by PHS Research Grant 1-R01-WH-16856-02 from the Behavioral Science Research Branch, National Institute of Mental Health, to the first author. The authors are grateful to Moshe Anisfeld and Julian Hochberg for their critical reading of an earlier version of this paper.

$\div$ Requests for reprints should be sent to Carl Auerbach, Department of Psychology, Yeshiva University. New York, New York 10003.
}

(Luce, 1963) and to provide evidence for the correctness of this model. Second, to use the model to demonstrate that set acts preperceptually, at least in certain instances. Third, to clarify the manner in which set acts postperceptually.

The model we shall use will be applied to experiments which compare performances when set is administered prior to stimulation. after stimulation. and not administered at all, an experimental paradigm first used by Chapman (1932). Let us call these conditions. respectively, the "pre," "post," and "control" conditions. The performance measured in each condition is $\mathrm{P}(\mathrm{C})$. the probability of a correct response. Let $\mathrm{P}(\mathrm{C} / \mathrm{pre}) . \mathrm{P}(\mathrm{C} /$ post $)$, and $\mathrm{P}(\mathrm{C} /$ control $)$ be the value of $\mathrm{P}(\mathrm{C})$ in the pre, post, and control conditions, respectively. Set may be assumed to operate if $\mathrm{P}(\mathrm{C} /$ control $)$ is less than the other two probabilities. The locus of its effect, however, is not clear. If $\mathrm{P}(\mathrm{C} / \mathrm{pre}) \leqslant$ $\mathrm{P}(\mathrm{C} / \mathrm{post})$, then there is a presumption that set operates postperceptually, as the set is more effective when administered after perception has occurred. If $\mathrm{P}(\mathrm{C} / \mathrm{pre})$ $>\mathrm{P}(\mathrm{C} /$ post $)$, then no conclusions can be drawn. This result could be due to set's facilitating a preperceptual process, but could equally be due to prestimulation set having more time to facilitate a postperceptual process. The experimental paradigm, however, can be analyzed so as to lead to more definite conclusions.

The first assumption we make is that of all-or-none processing. We assume that, in the conditions of the experiment, the subject will be either set, in State $S$, or not set, in State $\bar{S}$, with probabilities $P(S)$ and $P(\bar{S})=$ $1-\mathrm{P}(\mathrm{S})$, respectively. Let $\mathrm{P}(\mathrm{C})$ be the overall probability that the $S$ responds correctly, and $\mathrm{P}(\mathrm{C} / \mathrm{S})$ and $\mathrm{P}(\mathrm{C} / \overline{\mathrm{S}})$ be the conditional probabilities that the subject responds correctly given that he is in State $S$ or $\bar{S}$, respectively. It follows from the laws of conditional probability that

$$
\mathrm{P}(\mathrm{C})=\mathrm{P}(\mathrm{S}) \mathrm{P}(\mathrm{C} / \mathrm{S})+[1-\mathrm{P}(\mathrm{S})] \mathrm{P}(\mathrm{C} / \overline{\mathrm{S}}) .
$$

Let $\mathrm{P}(\mathrm{C} / \mathrm{pre})$ and $\mathrm{P}(\mathrm{C} /$ post $)$ be the probability that the 
subject responds correctly in the pre and post conditions, respectively, and $s_{1}$ and $s_{2}$ be the value of $\mathrm{P}(\mathrm{S})$ in the pre and post conditions, respectively. Writing Eq. 1 separately for the pre and post conditions yields

$$
\begin{gathered}
\mathrm{P}(\mathrm{C} / \text { pre })=\mathrm{s}_{1} \mathrm{P}(\mathrm{C} / \mathrm{S})+\left(1-\mathrm{s}_{1}\right) \mathrm{P}(\mathrm{C} / \overline{\mathrm{S}}) \\
\mathrm{P}(\mathrm{C} / \text { post })=\mathrm{s}_{2} \mathrm{P}(\mathrm{C} / \mathrm{S})+\left(1-\mathrm{s}_{2}\right) \mathrm{P}(\mathrm{C} / \overline{\mathrm{S}}) .
\end{gathered}
$$

Equations 2 may be used to solve for $\mathrm{P}(\mathrm{C} / \mathrm{pre})$ in terms of $\mathrm{P}(\mathrm{C} / \mathrm{post})$, the result being

$$
\begin{aligned}
\mathrm{P}(\mathrm{C} / \mathrm{pre}) & =\frac{1-\mathrm{s}_{1}}{1-\mathrm{s}_{2}} \mathrm{P}(\mathrm{C} / \text { post })+\frac{\mathrm{s}_{1}-\mathrm{s}_{2}}{1-\mathrm{s}_{2}} \mathrm{P}(\mathrm{C} / \mathrm{S}) \\
& =\mathrm{m}_{1,2}+\mathrm{b}_{1,2},
\end{aligned}
$$

where $m_{1,2}$ and $b_{1,2}$ are defined implicitly by Eq. 3 .

Equation 3 reveals that, if the assumption of all or none processing is correct, $\mathrm{P}(\mathrm{C} / \mathrm{pre})$ is a linear function of $\mathrm{P}(\mathrm{C} /$ post $)$. Moreover, the value of $\mathrm{P}(\mathrm{C} / \mathrm{S})$ may be determined once $m_{1,2}$ and $b_{1,2}$ are known. Note, finally, that $\mathrm{P}(\mathrm{C} / \mathrm{pre})$ may exceed $\mathrm{P}(\mathrm{C} /$ post $)$ even when $s_{2}$, the probability that the subject is set postperceptually, does not equal 0 . This is a quantitative statement of the earlier argument that set being more effective when administered before stimulation than after stimulation does not prove that set cannot operate postperceptually.

The second assumption we make is that, in the $\bar{S}$ state, stimulus information and context information interact independently in the response process. Specifically, let $\mathrm{k}$ equal the probability that the subject makes a correct response in the absence of any stimulus information, i.e., given only the knowledge of the alternative responses provided by the set itself. $\mathrm{P}(\mathrm{C} /$ control $)$ is equal to the probability that the subject responds correctly given just the stimulus information, as there is no context information provided by the set in the control condition. The second assumption, then, is that

$$
\mathrm{P}(\mathrm{C} / \overline{\mathrm{S}})=\mathrm{P}(\mathrm{C} / \text { control })+\mathrm{k}-\mathrm{kP}(\mathrm{C} / \text { control }) .
$$

Equation 4 is simply the rule for the combination of two independent probabilities, and some empirical evidence for it has been presented by Rubinstein and Pollack (1963) and by Tulving, Mandler, and Baumal (1964).

When Eq. 4 is substituted into Eqs. 2, the result is

$$
\begin{aligned}
\mathrm{P}(\mathrm{C} / \text { pre })= & \left(1-\mathrm{s}_{1}\right)(1-\mathrm{k}) \mathrm{P}(\mathrm{C} / \text { control }) \\
& +\left[\mathrm{s}_{1} \mathrm{P}(\mathrm{C} / \mathrm{S})+\left(1-\mathrm{s}_{1}\right) \mathrm{k}\right] \\
= & \mathrm{m}_{1,0} \mathrm{P}(\mathrm{C} / \text { control })+\mathrm{b}_{1,0} \\
\mathrm{P}(\mathrm{C} / \text { post })= & \left(1-\mathrm{s}_{2}\right)(1-\mathrm{k}) \mathrm{P}(\mathrm{C} / \text { control })
\end{aligned}
$$

$$
\begin{gathered}
+\left[\mathrm{s}_{2} \mathrm{P}(\mathrm{C} / \mathrm{S})+\left(1-\mathrm{s}_{2}\right) \mathrm{k}\right] \\
=\mathrm{m}_{2,0} \mathrm{P}(\mathrm{C} / \text { control })+\mathrm{b}_{2,0},
\end{gathered}
$$

where $m_{1,0}, b_{1,0}, m_{2,0}$, and $b_{2,0}$ are defined implicitly in Eq. 5. Equations 5 are like Eq. 3 in that two of the experimentally measured probabilities, $\mathrm{P}(\mathrm{C} / \mathrm{pre})$ and $\mathrm{P}(\mathrm{C} /$ post $)$ are linear functions of the third, $\mathrm{P}(\mathrm{C} / \mathrm{control})$.

There is, moreover, a consistency condition relating Eqs. 3 and 5, namely that

$$
\mathrm{m}_{1,2}=\frac{\mathrm{m}_{1,0}}{\mathrm{~m}_{2,0}}
$$

Equation 6 may be tested. Note that this condition is somewhat more subtle than it first appears. If any two variables are linear functions of a third, then they are also linear functions of each other, and a relationship between the slopes like that of Eq. 6 holds. However, given real data, it is possible to generate three random sets of probabilities, fit three straight lines to them using a least squares method, and not have Eq. 6 obtain. Thus, confirmation of Eq. 6 by actual data is nontrivial.

There is, further, another consistency condition which follows from the analysis, namely a relationship between the slopes and intercepts of the hypothesized linear relationships. We shall not examine the condition in its complete generality, although it is easy enough to do so, but consider only the case when $\mathrm{P}(\mathrm{C} / \mathrm{S})=1$, for which we shall later provide empirical evidence. If $P(C / S)=1$, it follows that

$$
\begin{aligned}
& m_{1,2}+b_{1,2}=1 \\
& m_{1,0}+b_{1,0}=1 \\
& m_{2,0}+b_{2,0}=1 .
\end{aligned}
$$

We are, moreover, in a position to determine the values of $s_{1}$ and $s_{2}$, assuming the existence of the linear relations of Eqs. 5 . When the values of the slopes $m_{1,0}$ and $m_{2,0}$ are known, the values of $s_{1}$ and $s_{2}$ are then given by

$$
\begin{aligned}
& \mathrm{s}_{1}=1-\frac{\mathrm{m}_{1,0}}{1-\mathrm{k}} \\
& \mathrm{s}_{2}=1-\frac{\mathrm{m}_{2,0}}{1-\mathrm{k}} .
\end{aligned}
$$

Equation 8 is helpful only if the value of $k$ is known. To anticipate our results somewhat, it will emerge that $\mathrm{k}$ may be inferred from certain features of the data. Equation 8, then, may be used to solve for $s_{1}$ and $s_{2}$ and, in particular, to decide if $s_{2}=0$, that is. if postperceptual set is not operative. 
It is perhaps worthwhile to review which of our predictions are tests of which of our assumptions. The linear relationship predicted by Eq. 3 follows from the assumption of all-or-1none processing and. if obtained. may be regarded as a test of this assumption. The linear relationships predicted in Eqs. 5 follow from assuming both all-or-none processing and independence of stimulus and context information and, if obtained. may be regarded as confirming both of them. There are two consistency conditions. namely Eqs. 6 and 7, which also follow only if both assumptions are made, and these. if met. provide further support for both assumptions. Equation 8, finally: enables one to evaluate the probability that the subject is set by pre- and poststimulation cuing. and thus be able to make inferences about the nature of the effect of set on pereeption. Use of Eq. 8 in this way presupposes that the assumptions from which it is derived have been confirmed.

The aim of the present experiments is to examine the theoretical predictions proposed here. Two experiments are reported. The first one deals with simple auditory discrimination in which. by its nature, no control condition was possible. The second one deals with phoneme identification. in which complete comparisons of the pre. post. and control conditions were made.

\section{EXPERIMENT I: AUDITORY DISCRIMINATION}

The first experiment investigates a simple auditory discrimination task. A two-interval forced-choice discrimination task was used in which the stimuli could differ in frequency and/or intensity and Ss were instructed which dimension to discriminate either before stimulation (the pre condition) or after stimulation (the post condition)

\section{Method}

\section{Stimuli}

Ss were required to judge either which of two pure tones presented was higher in frequency or which was greater in intensity. Each tone could have one of two frequencies. 1,500 or $1.512 \mathrm{~Hz}$, and one of two intensities. 80 or $81 \mathrm{~dB}$. The tones were presented monaurally through Grason-Stadler TD H39-10Z earphones to $\mathrm{Ss}$ seated in an Industrial A coustics Model 400-A sound-attenuating chamber. The tones were produced by Hewlett-Packard Model 204C oscillators. Frequencies were monitored with a Monsanto Model 100-A frequency counter and were constant to within $1 \mathrm{~Hz}$. Intensities were measured with a Balantine Model $300 \mathrm{H}$ voltmeter and were constant to within the accuracy of the instrument. The duration of each tone was $200 \mathrm{msec}$. The interstimulus interval was $1 \mathrm{sec}$.

\section{Procedure}

A two-interval forced-choice discrimination task was used One of the two possible discriminations, frequency or intensity. was required on a trial. The discrimination required of the $S$ was indicated to him by illumination of one of two lights situated on a panel in front of him. The $S$ reported his judgment of which interval contained the higher frequency or higher intensity tone by pressing a button on a panel in front of him corresponding to the first or second interval.

There were four instructional conditions. In the pre(2) and pre $\left({ }^{1}=\right)$ conditions, the discrimination to be made was indicated to the $S 2$ or $1 / 2 \mathrm{sec}$ before presentation of the stimuli. In the post $\left({ }^{1}\right)$ and post $(4)$ conditions, the discrimination to be made was indicated to the $S 1:$ or $4 \mathrm{sec}$ after presentation of the stimuli. A typical sequence of events during a pre trial was as follows. A warning light was illuminated for $500 \mathrm{msec}$, and immediately afterwards an instructional light was illuminated for $50 \mathrm{msec}$. After a $2-$ or $1 / 2$-sec interval, the stimuli were presented and the $S$ could respond with the appropriate discrimination. A typical sequence of events during a post trial was as follow's. A warning light was illuminated and immediately afterwards the stimuli were presented. One half or $4 \mathrm{sec}$ later. an instructional light was illuminated and $S$ s could respond with the appropriate discrimination.

There were three stimulus conditions. In the simply variant (SV) condition, the dimension not discriminated was held constant at its lower value. In the directly variant (DV) condition, the higher frequency tone was also of greater intensity. In the inversely variant (IV) condition, the higher frequency tone was of lower intensity.

The experiment lasted for 6 days. Each daily session lasted 1 h and was divided into four blocks. Each day. the $\mathrm{S}$ received a permutation of the instructional conditions, one instructional condition in each block. The order of conditions over davs was balanced so that every instructional condition occurred equally often in each block. In order to prevent $S$ s from catching on to correlations between frequency and intensity, the stimulus conditions were randomly interspersed among instructional conditions. The nature of the stimuli, the attribute to be discriminated. and the interval which was the correct response were programmed so that (i) each stimulus condition occurred equally often within each instructional condition. (ii) there were an equal number of judgments of frequency and intensity, and (iii) the number of times the first interval response was correct was equal to the number of times the second interval response was correct.

Consequently, the experiment had the form of a 4 by 3 by 2 factorial experiment. namely Instructions by Stimuli by Judgment, with repeated measures on all three factors. Ninety-six responses went into the probabilities for each cell.

\section{Subjects}

Six paid Ss served in the experiment. None had any hearing deficit.

\section{Rationale}

In running the experiment, we had a choice of whether to use extremely practiced $S s$ or naive Ss. It was our decision not to give $S$ s lots of practice at the task, but instead to run the experiment in such a fashion as to minimize learning. Consequently, the entire experiment was run without feedback to the $S$ s. In view of this, certain experimental design considerations were followed. The amplitude discrimination level was chosen so as to be rather difficult. as research has shown that little learning is to be expected in amplitude discrimination (Gundy, 1971). On the other hand. the frequency discrimination was taken to be a rather easy one for practiced Ss, as research has shown that extensive practice with feedback is required before $\mathrm{S} s$ reach asymptotic frequency discrimination (Auerbach. 1971 a).

\section{Results}

In analyzing the data, the observed values of $\mathrm{P}(\mathrm{C} / \mathrm{pre})$ 


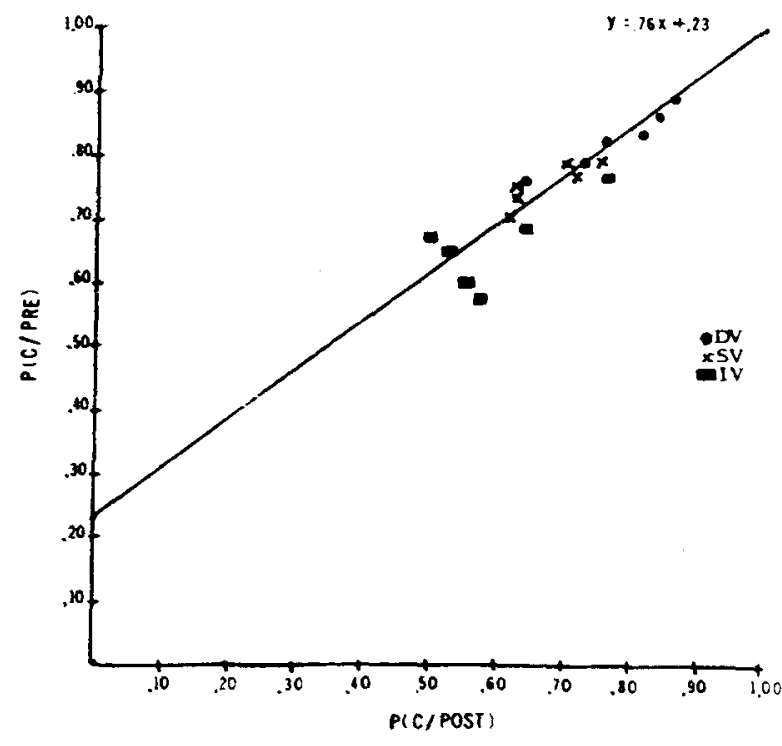

Fig. 1. Probability of a correct response in the precuing condition as a function of probability of a correct response in the postcuing condition. The line of best fit is also shown. Data are for individual $S s$ in the auditory discrimination experiment. The three stimulus conditions are separately indicated.

and $\mathrm{P}(\mathrm{C} /$ post $)$ were corrected for interval bias, using a procedure described by Auerbach (1971b), and these corrected values were used in subsequent analysis. As anticipated, preliminary inspection of the data revealed no difference between frequency and intensity discrimination. Thus, frequency and intensity judgments were pooled, reducing the experiment to a 4 by 3 factorial experiment, namely Instructions by Stimuli, with repeated measures on both factors. A total of 192 responses went into the probabilities for each cell.

The appropriate analysis of variance was performed (Myers, 1966, p. $152 \mathrm{ff}$ ). There was a significant main effect of instructions $[F(3,15)=21.12, p<.01]$ and of stimuli $[F(2.10)=19.42, p<.01]$. There was no significant Instructions by Stimuli interaction. The significant main effect of instructions was in the direction $\mathrm{P}(\mathrm{C} / \mathrm{pre})>\mathrm{P}(\mathrm{C} /$ post $)$, and the significant main effect of stimuli was, in order of difficulty, DV, SV, and IV.

The instructional conditions within the pre and post conditions were separately compared, i.e., pre(2) vs pre( $(1 / 2)$ and post $(1 / 2)$ vs post (4), using a repeated measures analysis of variance and considering the two instructional conditions as two levels of one treatment factor. There was no significant main effect of instructions, and no significant Instructions by Stimuli interaction. The main effects of stimuli remained significant, namely $F(2.10)=20.82 . p<.01$ in the pre condition and $F(2.10)=16.20, p<.01$ in the post condition.

As there was no difference between the two instructional conditions in either the pre or the post conditions, data from the two levels of the pre condition were pooled. as were data from the two levels of the post condition. The number of observations constituting each data point, then, was 384 . For each $\mathrm{S}, \mathrm{P}(\mathrm{C} / \mathrm{pre})$ in each stimulus condition was plotted as a function of $P(C /$ post $)$ in the same stimulus condition. A straight line was fit to the data, using the method of least squares (Hays, 1963, p. 505). The result, shown in Fig. 1 , is

$$
\mathrm{P}(\mathrm{C} / \mathrm{pre})=0.76 \mathrm{P}(\mathrm{C} / \text { post })+0.23 \text {. }
$$

In order to evaluate the goodness of fit of the linear relationship of Eq. 9, a modification of trend analysis was employed. The right hand probability, $\mathrm{P}(\mathrm{C} / \mathrm{post})$, was treated as an independent variable, each level of which defined a column in a single-factor experiment. The left-hand probability, $\mathrm{P}(\mathrm{C} / \mathrm{pre})$, was treated as the mean of a discrete, two-valued variable, whose value was 1 if the S's response was correct and 0 if it was incorrect. Thus, using the procedures described by Hays (1963, p. 545), the between-cell variance was partitioned into its linear and nonlinear components, and each was separately tested for significance. The analysis of variance was done using a routine application of the analysis of variance to binary data. This procedure was employed rather than an application of the chi-square technique (Lewis \& Burke, 1949), as the theoretical issue being evaluated was the presence and strength of a linear relationship rather than the goodness of fit of a particular linear relationship.

There was, in fact, a significant linear relationship, the appropriate value of $F$ being $F(1,6894)=197.95$, $\mathrm{p}<.01$. There was, in addition, a significant nonlinear relationship, the appropriate value of $F$ being $F(16,6894)=3.48, p<.01$.

In order to get an estimate of how much of the variance is accounted for by the linear relationship, the percentage of the variance accounted for by the linear relationship was divided by the percentage of the variance accounted for by the between-cell effects, both computed using the procedures described by Hays (1963, p. 546). In fact, the linear relationship accounted for $83 \%$ of the accounted-for variance.

\section{Discussion}

The data support portions of the model proposed here. The linear relationship obtained between $\mathrm{P}(\mathrm{C} / \mathrm{pre})$ and $P(C /$ post $)$ supports the two-state hypothesis of which Eq. 3 is a consequence. The presence of a significant nonlinear relationship poses problems for this interpretation, but as no systematic deviations from linearity are apparent from inspection of the data, and as $83 \%$ of the accounted-for variance is accounted for by the linear relationship. we do not see any reason to reject the model.

We remark, parenthetically, that it is possible to solve for $\mathrm{P}(\mathrm{C} / \mathrm{S})$ from $\mathrm{Eq} .3$. When this is done, the result is 
$\mathrm{P}(\mathrm{C} / \mathrm{S})=0.96$, which is, to a first approximation, 1 . This suggests that Ss, when "set," at least in the conditions of this experiment, will always respond correctly. Alternatively, one may take it as axiomatic that $P(C / S)=$ 1, upon which the first equation of Eqs. 7 follows as a prediction. As the slope and intercept of Eq. 9 add up to 0.99 , which is approximately 1 , we could then take this as further support of the model.

\section{EXPERIMENT II: PHONEME IDENTIFICATION}

The aim of the second experiment was to investigate a situation in which all three of the pre, post, and control conditions could be used. This enables us to evaluate both assumptions in the model presented here and also to specifically investigate the values of $s_{1}$ and $s_{2}$.

\section{Method}

\section{Stimuli}

Twenty phonemes made up of consonants and semivowels were paired with both $/ \mathrm{a} /$ and $/ \partial /$ vowels to yield $40 \mathrm{CV}$ syllables. The stimulus in each of the conditions consisted of a tape made by recording the $40 \mathrm{CV}$ syllables in a random order, with each syllable presented four times. Thus, within the 160 presentations, each phoneme occurred eight times. Three such tapes were made, one for the control condition and two for the experimental conditions.

The stimuli and electronically generated white noise were recorded separately on two channels of a Tandberg Model 74 stereo tape recorder. The outputs were mixed and presented binaurally to $S s$ through Lafayette F 767 stereo headphones. The peak speech-signal-to-noise ratio was $-10 \mathrm{~dB}$.

\section{Procedure}

Ss were first familiarized with the set of CV syllables. They were also instructed as to a phonetic spelling of each syllable to be used for writing down what they had heard. Each $S$ was presented with a randomly chosen sequence of the pre, post, and control conditions.

Each $S$ in the control condition listened to the control tape. Half the Ss heard Experimental Tape 1 in the pre condition and Experimental Tape 2 in the post condition. The remaining half heard Tape 2 in the pre condition and Tape 1 in the post condition.

In the control condition, Ss were simply required to listen to the tape and write down which CV syllable they had heard. The response time, in this case the intersyllable interval, was $4 \mathrm{sec}$.

In both the pre and post conditions, the "set" consisted of four CV syllables. One of the syllables was the critical phoneme in a vowel context and the other three consisted of three alternative phonemes selected randomly from the 20 phoneme set in the same vowel context. The four CV syllables for each of the 160 syllables on the stimulus tape were typed phonetically on an index card, and the cards were separated by covering cards numbered sequentially from 1 to 160 .

In the precuing condition, Ss were instructed that when they heard a number (from 1 through 160 ) presented in sequential order clearly on the tape, they were to flip over the appropriate cover card and read to themselves the four possible alternatives. They were allowed $3 \mathrm{sec}$ for this. After $1 \mathrm{sec}$, a syllable in noise was presented, and the $S s$ had to write down which of the alternative syllables they had heard. There was a 4-sec response interval.

In the postcuing condition, the stimulus in noise was presented first. Within $1 \mathrm{sec}$, the Ss heard a number in sequential

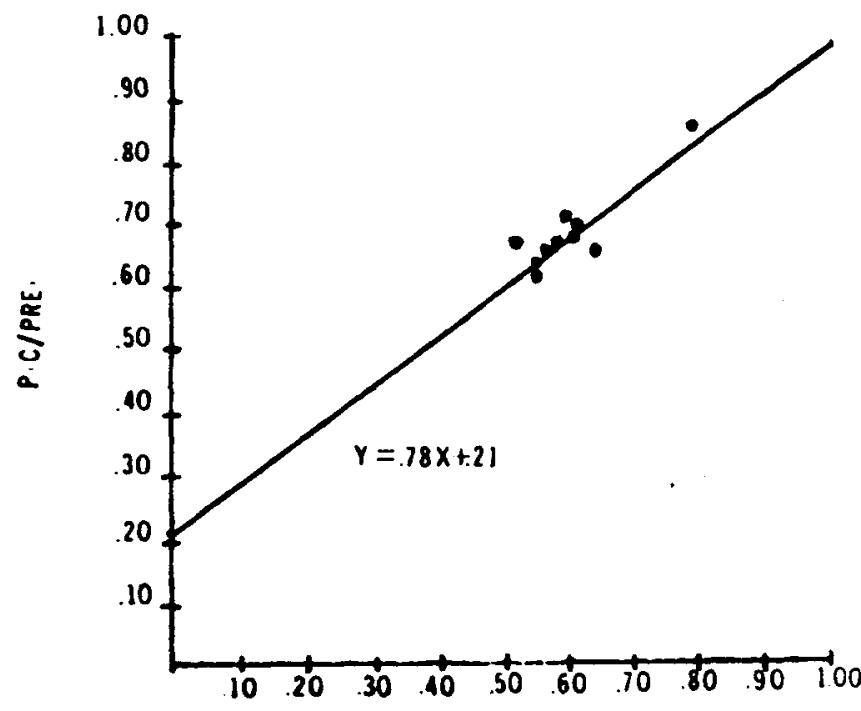

\section{PIC/POST)}

Fig. 2. Probability of a correct response in the precuing condition as a function of probability of a correct response in the postcuing condition. The line of best fit is also shown. Data are for individual $\mathrm{Ss}$ in the phoneme identification experiment.

order from 1 to 160 and were instructed to flip over the appropriate cover card and read the four possible alternatives to themselves. Within a $4-\sec$ response interval, Ss were required to write down which of the alternatives they had heard.

\section{Subjects}

Ten paid volunteers with normal hearing acted as Ss for this experiment.

\section{Results}

The frequency of correct identifications of the $\mathrm{CV}$ syllables was computed for each $S$ in each condition and taken as an estimate of $\mathrm{P}(\mathrm{C} / \mathrm{pre}), \mathrm{P}(\mathrm{C} /$ post $)$, and $\mathrm{P}(\mathrm{C} /$ control $)$. The treatment means of each condition were $\mathrm{P}(\mathrm{C} / \mathrm{pre})=0.680, \mathrm{p}(\mathrm{C} /$ post $)=0.606$, and $\mathrm{P}(\mathrm{C} /$ control $)=0.529$. The order of conditions then is $\mathrm{P}(\mathrm{C} /$ pre $)>\mathrm{P}(\mathrm{C} /$ post $)>\mathrm{P}(\mathrm{C} /$ control $)$. An analysis of variance appropriate to the repeated measures design was performed (Myers, 1966, p. 152ff), which indicated a significant treatment effect $[F(2,27)=11.4, p<.01]$. Separate $t$ tests revealed that each difference between treatment means was significant.

Separate straight lines were fit to the functions $\mathrm{P}(\mathrm{C} / \mathrm{pre})$ vs $\mathrm{P}(\mathrm{C} /$ post $), \mathrm{P}(\mathrm{C} / \mathrm{pre})$ vs $\mathrm{P}(\mathrm{C} /$ control $)$, and $\mathrm{P}(\mathrm{C} /$ post $)$ vs $\mathrm{P}(\mathrm{C} /$ control $)$, Eqs. 3 and 5 , using the least squares method (Hays, 1963, p. 505). The results, shown in Figs. 2, 3, and 4, were

$$
\begin{gathered}
\mathrm{P}(\mathrm{C} / \text { pre })=0.78 \mathrm{P}(\mathrm{C} / \text { post })+0.21 \\
\mathrm{P}(\mathrm{C} / \text { pre })=0.58 \mathrm{P}(\mathrm{C} / \text { control })+0.37 \\
\mathrm{P}(\mathrm{C} / \text { post })=0.79 \mathrm{P}(\mathrm{C} / \text { control })+0.19
\end{gathered}
$$




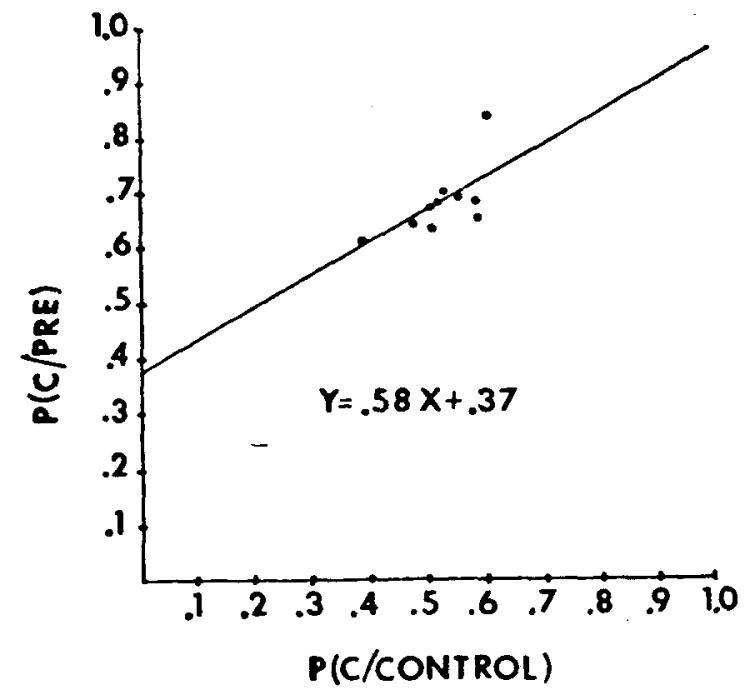

Fig. 3. Probability of a correct response in the precuing condition as a function of probability of a correct response in the control condition. The line of best fit is also shown. Data are for individual $\mathrm{Ss}$ in the phoneme identification experiment.

In order to evaluate the goodness of fit of the linear relationships of Eq. 10, the modification of trend analysis used in Experiment I was employed. In each case, there was a significant linear relationship. For $\mathrm{P}(\mathrm{C} /$ pre $)$ vs $\mathrm{P}(\mathrm{C} /$ post $), \mathrm{F}(1,1590)=21.00, \mathrm{p}<.01 ;$ for $\mathrm{P}(\mathrm{C} / \mathrm{pre})$ vs $\mathrm{P}(\mathrm{C} /$ control $), \mathrm{F}(1,1590)=10.96, \mathrm{p}<.01$; and for $\mathrm{P}(\mathrm{C} /$ post $)$ vs $\mathrm{P}(\mathrm{C} /$ control $), \mathrm{F}(1,1590)=14.580$, $\mathrm{p}<.01$. There were, however, significant nonlinear relationships in two of the equations. For $\mathrm{P}(\mathrm{C} / \mathrm{pre})$ vs $\mathrm{P}(\mathrm{C} /$ post $), \mathrm{F}(8,1590)=2.82, \mathrm{p}<.01 ;$ and for $\mathrm{P}(\mathrm{C} /$ pre $)$ vs $\mathrm{P}(\mathrm{C} /$ control $), \mathrm{F}(8,1590)=2.07, \mathrm{p}<.05$. However, for $\mathrm{P}(\mathrm{C} /$ post $)$ vs $\mathrm{P}(\mathrm{C} /$ control $), \mathrm{F}(8,1590)=1.48$, which was not significant.

In order to get some estimate of how much of the variance is accounted for by the linear relationship, the proportion of the variance accounted for by the linear relationship was divided by the proportion of the total variance accounted for by the between-cell effects, in the same way as was done in Experiment I. For $\mathrm{P}(\mathrm{C} / \mathrm{pre})$ vs $\mathrm{P}(\mathrm{C} /$ post $)$, the linear relationship accounted for $58 \%$ of the accounted-for variance; for $\mathrm{P}(\mathrm{C} / \mathrm{pre})$ vs $\mathrm{P}(\mathrm{C} /$ control $)$, the linear relationship accounted for $54 \%$ of the accounted-for variance; and for $\mathrm{P}(\mathrm{C} / \mathrm{post})$ vs $\mathrm{P}(\mathrm{C} /$ control $)$, the linear relationship accounted for $78 \%$ of the accounted-for variance.

\section{Discussion}

The data support the model proposed here. The linear relationship obtained between $\mathrm{P}(\mathrm{C} / \mathrm{pre})$ and $\mathrm{P}(\mathrm{C} /$ post $)$ supports the two-state hypothesis of Eq. 3. The presence of a significant nonlinear relationship poses problems for this interpretation, but as no systematic deviations from linearity are apparent from inspection of the data, and as $58 \%$ of the accounted-for variance is accounted for by the linear relationship, we do not see any reason to reject the mode!.

The linear relationships between $\mathrm{P}(\mathrm{C} / \mathrm{pre})$ and $\mathrm{P}(\mathrm{C} /$ control $)$ and between $\mathrm{P}(\mathrm{C} /$ post $)$ and $\mathrm{P}(\mathrm{C} /$ control $)$ provide additional support for the two-state hypothesis. and also support the independence of stimulus and context hypothesis from which Eq. 5 was derived. The presence of a significant nonlinear relationship between $\mathrm{P}(\mathrm{C} / \mathrm{pre})$ and $\mathrm{P}(\mathrm{C} /$ control $)$ and between $\mathrm{P}(\mathrm{C} / \mathrm{pre})$ and $\mathrm{P}(\mathrm{C} / \mathrm{post})$ does pose some problems for this interpretation, but, in view of the fact that no systematic deviations from linearity are apparent and that $54 \%$ and $58 \%$ of the accounted-for variance is accounted for by the linear relationship, we again see no reason to reject the model.

Additional support for the model is obtained by examining the two consistency conditions. For Eq. 6 , the actual value of $m_{1,2}$ is 0.78 and the anticipated value, i.e., $\mathrm{m}_{1,0} / \mathrm{m}_{2,0}$ is 0.75 , which agrees closely. For Eqs. 7, the actual sums of slopes and intercepts are 0.99 for $\mathrm{P}(\mathrm{C} /$ pre $)$ vs $\mathrm{P}(\mathrm{C} /$ post $), 0.95$ for $\mathrm{P}(\mathrm{C} / \mathrm{pre})$ vs $\mathrm{P}(\mathrm{C} /$ control $)$, and 0.98 for $\mathrm{P}(\mathrm{C} /$ post $)$ vs $\mathrm{P}(\mathrm{C} /$ control $)$, all of which agree closely with the predicted value of 1 . Note, too, that the verification of these consistency conditions provides further support for our minimizing the presence of the significant nonlinearities.

Equation 8 may be used to solve for $s_{1}$ and $s_{2}$ provided $k$ is known. Observation of the response protocols reveals that Ss use all of the four alternatives the set provides them and, in addition, sometimes do not respond at all. The simplest assumption to make, then, is that Ss are choosing from a set of five responses, four of them being the responses provided by the set and the fifth being "no response." This suggests that $k$, the probability of being correct using just the set

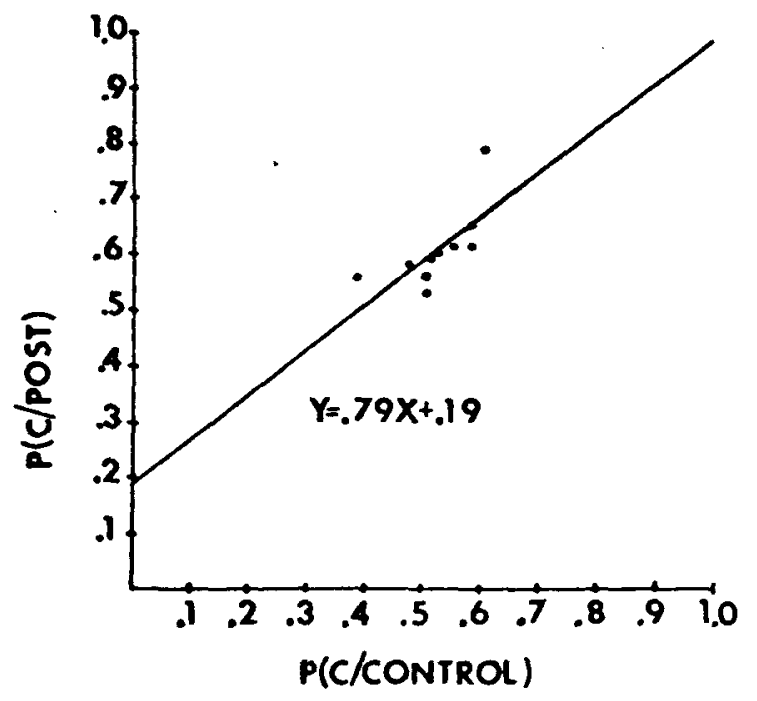

Fig. 4. Probability of a correct response in the postcuing condition as a function of probability of a correct response in the control condition. The line of best fit is also shown. Data are for individual $S s$ in the phoneme identification experiment. 
information, is equal to one-fifth. When this is substituted into Eq. 8, the result is

$$
\begin{aligned}
& s_{1}=0.27 \\
& s_{2}=0.01 .
\end{aligned}
$$

In this case, $s_{2}$ is sufficiently close to 0 to make $s_{2}=0 \mathrm{a}$ reasonable estimate.

\section{CONCLUSIONS}

The data and their analysis permit several conclusions. First, the two-state theory of set is at least a good approximation to the true state of affairs; that is, at least under the conditions of this experiment, subjects are either in a set state, $S$, or in a nonset state, $\bar{S}$. Secondly, in Experiment II, at any rate, subjects may be put into the set state only by prestimulation cuing. That is, the probability of being set in the post condition, $s_{2}$, is approximately 0 . The data do not permit us to draw any inferences about the response process in the set state, because we found that $P(C / S)=1$ in all experiments. In the $\overline{\mathbf{S}}$ state, we found that the set information and the stimulus information act independently to produce a response. This is consistent with a guessing model of the sort considered by Broadbent (1967).

The fact that $s_{2}=0$, that is, that subjects can be put into the $S$ state only by preperceptual stimulation, seems most consistent with the idea that being set involves engaging in some sort of preperceptual process, a process, that is, which cannot be facilitated by postperceptual stimulation. The data do not, of course, allow us to draw inferences concerning the nature of this process.

We note, however, that the set information also may act postperceptually, but does so in a very different way than when it acts preperceptually, namely altering the probability that subjects guess a correct response on the basis of partial perceptions.

\section{REFERENCES}

Auerbach, C. Improvement of frequency discrimination with practice: An attentional model. Organizational Behavior \& Human Performance, 1971a, 6, 316-335.

Auerbach, C. Correcting two-alternative forced-choice data for response bias. Perceptual \& Motor Skills, 1971b, 32, 533-534.

Broadbent, D. E. Word frequency effect and response bias. Psychological Review, 1967, 74, 1-15.

Chapman, D. W. Relative effects of determinate and indeterminate Aufgaben. American Journal of Psychology, 1932, 44, 163-174.

Egeth, H. Selective attention. Psychological Bulletin, 1967, 67, 41-57.

Gundy, R. F. Auditory detection of an unspecified signal. Journal of the Acoustical Society of America, 1961, 33, 1008-1012.

Haber, R. N. The nature of the effect of set on perception. Psychological Review, 1966, 73, 335-350.

Hays, W. L. Statistics. New York: Holt, Rinehart \& Winston, 1963.

Kulpe, O. Versuche über Abstraktion. Berlin International Congress of Experimental Psychology, 1904, 56-68.

Lewis, D. L., \& Burke, C. J. Use and misuse of the chi-square test. Psychological Bulletin, 1949, 46, 433-489.

Luce, R. D. A threshold theory for simple detection experiments. Psychological Review, 1963, 70, 61-79.

Myers, J. L. Fundamentals of experimental design. Boston: Allyn \& Bacon, 1966.

Rubinstein, H., \& Pollack, I. Word predictability and intelligibility. Journal of Verbal Learning \& Verbal Behavior, $1963,2,147-158$.

Swets, J. A., \& Sewall, S. T. Stimulus versus response uncertainty in recognition. Journal of the Acoustical Society of America, 1963, 33, 1586-1592.

Tulving, E., Mandler, G., \& Baumal, R. Interaction of two sources of information in tachistoscopic word recognition. Canadian Journal of Psychology, 1964, 18, 62-71.

(Received for publication January 26, 1973; accepted March 12, 1973.) 